\title{
INDULTO PRESIDENCIAL Y TERRORISMO
}

\author{
SUMARIO
}

I. Discurso en el Senado, de 23.03.1991. 1. Presos políticos. 2. Facultad de indultar. 3. Responsabilidades. 4. Posición de la UDI. II. Discurso en el Senado, de 08.01.1991: 1. Indulto, amnistía y' libertad provisional. 2. Análisis jurídico. 3. Peligro para la sociedad. 4. Error de 1925. 5. Juzgamiento adecuado. 6. Interrogante a futuro. 7. Responsabilidad del Estado. 8. Conductas políticas. 9. Las 54 reformas. 10. Estabilidad institucional.

\section{DISCURSO EN EL SENADO, DE 23.3.1991}

Los parlamentarios de la Unión Demócrata Independiente (UDI) asumimos el imperativo de conciencia de rechazar el proyecto de reforma constitucional sobre el cual hoy se pronuncia el Congreso Pleno.

Durante el debate de este proyecto en ambas ramas del Congreso, la posición de nuestro partido fue expuesta en forma detenida y fundada. Reafirmamos aquí esas intervenciones y nos remitimos a ellas para un conocimiento más completo de nuestro punto de vista.

Como entonces lo manifestamos, el proyecto en cuestión contiene algunos aspectos que nos parecen plausibles, con las salvedades y reservas que en esa ocasión señalamos.

Sin embargo, la médula de esta iniciativa radica en la auribución que se concede al presidente de la República para indultar terroristas, por delitos de ese carácter cometidos antes del 11 de marzo de 1990.

*Como homenaje al profesor Jaime Guzmán Errázuriz, senador de la República, asesinado el 1 de abril de 1991, al salir de su clase de Derecho Constitucional, que venía de dictar en la Facultad de Derecho de la Universidad Católica, se publica su último discurso en el Senado (23.3.1991), con ocasión del Congreso Pleno que votaba la reforma constitucional concediendo atribuciones al Presidente de la República para otorgar induitos a terroristas; se incluye, asimismo, su intervención en el Senado el día 8.1.1991, en la discusión de esa misma reforma constitucional.

Del profesor Jaime Guzmán esta Revista ha publicado su Seguridad nacional en la Constitución de 1980, Nos 37/38 (1985) 45-65. 
Se mantiene así, hacia el futuro, la sabia norma de la Constitución de 1980 que excluye del indulto presidencial a quienes sean condenados por delitos terroristas. Pero se le in troduce una excepción. Se permite dicho indulto, si se trata de delitos terroristas cometidos antes del 11 de marzo de 1990.

\section{Señor presidente:}

En estos días, han entrado en vigencia diversas normas destinadas a agilizar los procesos de personas procesadas por leyes especiales, en los que algunos equivocadamente denominan "presos políticos". Tales disposiciones incluyen importantes cambios de competencia.

Nuestro partido concurrió a aprobar esas modificaciones en ambas Cámaras, porque aún cuando los mal llamados "presos políticos" están inculpados de graves delitos, ellos merecen -como toda persona- un juzgamiento adecuado y justo.

\section{Presos politicos}

De consiguiente, sin necesidad de la reforma que hoy vota este Congreso Pleno, el Presidente de la República podría indultar a todos los denominados "presos políticos", una vez dictadas las sentencias respectivas, salvo exclusivamente a quienes sean o resulten condenados por delitos terroristas.

La ciudadanía debe saber así que esta iniciativa tiene por objeto preciso que el jefe del Estado también pueda indultar terroristas.

Cuando aludimos a terroristas, no formulamos ninguna apreciación subjetiva o controvertible. Nos referimos a personas condenadas judicialmente por delitos que la ley define como conductas terroristas, según el texto legal revisado y aprobado por este mismo parlamento. Son esas las únicas personas que sin esta reforma, no podrían beneficiarse con el indulto presidencial. Para permitir tal indulto de esas personas, que objetiva e incuestionablemente son terroristas, se ha impulsado la enmienda constitucional que hoy vota este Congreso Pleno.

Esta reforma tiene así como potenciales beneficiados al grupo más peligroso de los mal llamados "presos políticos", porque el eventual indulto de todos los demás no requeriría en absoluto de esta modificación constitucional.

Juzgamos que lo anterior es profundamente grave e inconveniente para el país. Por eso rechazamos esta reforma. 
Se pretende tranquilizar a la opinión pública, invocando la prudencia con que cabría presumir el ejercicio de esta atribución por el actual presidente de la República. La ciudadanía no debe dejarse confundir por ese argumento, ya que él arranca de un supuesto equivocado.

\section{Facultad de indultar}

Por una parte, la facultad de indultar a los referidos terroristas no se está confiriendo aquí sólo al actual jefe del Estado, sino también a quienes le sucedan en su cargo hacia el futuro. Aquellos terroristas que no sean acreedores al referido beneficio, conforme al criterio del presidente Aylwin, podrán ser así indultados por futuros gobernantes, cuyos criterios obviamente nadie puede adivinar. En consecuencia, no es admisible aprobar esta reforma ponderando sólo los enfoques o cualidades personales del actual jefe del Estado.

Pero hay más, señor presidente.

Consideramos que esta iniciativa representa un gigantesco error, del cual tal vez muy pronto tendrán que arrepentirse los propios sectores que hoy la están aprobando.

En efecto, si el actual Presidente de la República ejerce esta atribución en forma más restrictiva que lo comprometido en el programa de la Concertación, no indultando a terroristas que conforme a dicho documento deberían ser indultados, se generará una explicable presión de los grupos más extremos que apoyaron a don Patricio Aylwin como candidato presidencial. Los efectos de esas presiones, que pueden ser sangrientas, aparte de dañar a los afectados por ellas, no perjudicarán sólo al gobierno, sino al país entero.

Por el contrario, si el actual jefe del Estado se atiene al programa de la Concertación, otorgando el indulto con la amplitud establecida en su texto, quienes desde la oposición han contribuido a posibilitar la aprobación de esta reforma, no podrán eximirse de su propia responsabilidad respecto de tales indultos.

\section{Responsabilidades}

Cualquier intento por desligarse de esa responsabilidad, pretendiendo circunscribirla únicamente en el jefe del Estado, les sería replicado con la evidencia de que nadie podía dejar de prever que la facultad que hoy se otorgue al Presidente de la República se ejercería ciñéndose al programa que lo llevó a la primera magistratura de la Nación. 
Desde otra perspectiva, el año transcurrido desde marzo de 1990, nos demuestra, en forma tan elocuente como dramática, que la amenaza terrorista sigue vigente. La creencia de que el auvenimiento de la plenitud democrática hará desistir a los terroristas de sus desquiciados afanes, se ha visto crudamente contradicha por los hechos.

Mas aún, muchas de las personas que podrían ser beneficiadas por esta enmienda constitucional están vinculadas a las mismas agrupaciones que hoy continúan ejecutando y reivindicando crímenes o atentados terroristas, como el Frente Lautaro o el Frente Manuel Rodríguez.

El desafiante recrudecimiento del terrorismo se ve actualmente agudizado por el incremento de la delincuencia común, que también inquieta con creciente angustia a los chilenos. Los vasos comunicantes entre el terrorismo y la delincuencia común son suficientemente conocidos como para perfilar las reales dimensiones de tan delicado problema.

Estamos convencidos que la ciudadania observa con desconcierto y estupor que, en este preciso momento, el actual Congreso Pleno se reúna para ratificar — como la primera reforma constitucional que aprueba- una enmienda que permite el indulto presidencial de terroristas.

\section{Posición de la LDI}

Nuestro partido ha contribuido en este Congreso a muchas iniciativas tendientes a la reconciliación entre los chilenos. El país puede estar cierto que continuaremos haciéndolo, teniendo siempre presente que tan noble objetivo requiere una adecuada ecuación entre la generosidad y el realismo.

La reconciliación nacional exige especial acierto, tino y equilibrio en los instrumentos que se diseñen para lograrla. Consideramos que esta enmienda constitucional no cumple con esos requisitos, porque ningún paso tenderá efectivamente a dicha reconciliación, si él pone en peligro la seguridad de las personas o la paz social.

Señor presidente:

Votamos en contra de esta reforma constitucional, porque somos contrarios a que personas condenadas por delitos terroristas puedan ser indultados por la sola voluntad del presidente de la República cualquiera que ésta sea. 
Votamos en contra de esta reforma constitucional, porque tanto en la campaña electoral de 1989 como hoy, discrepamos del programa de la Concertación en materia de indultos. No podríamos sentirnos actuando de modo consecuente con ello, si concurriéramos a ampliar ahora el ámbito del indulto presidencial.

Votamos en contra de esta reforma constitucional, porque nos parece que ella envuelve una pésima e incomprensible señal para el país, cuando el recrudecimiento terrorista y de la delincuencia común reclama una actitud particularmente firme, y sin equívocos, de todas las autoridades públicas ante tan seria amenaza.

\section{DISCURSO EN EL SENADO, DE 8.1.1991}

\section{Indulto, amnistia y libertad provisional}

El señor Valdés (presidente).- Tiene la palabra el honorable señor Guzmán.

El señor Guzmán.-Señor Presidente, honorables colegas: desde la promulgación de la Carta de 1980, su texto contiene un precepto relativo al terrorismo, que se incluye entre las bases de la institucionalidad chilena. Se trata del artículo $9^{\circ}$ de la Constitución, que forma parte, así, del Capítulo I de ella.

Dicha norma introduce el concepto de "delito terrorista", entendiendo por tal aquellas conductas a las que una ley de quórum calificado les atribuya ese carácter y les fije la penalidad respectiva. En la exigencia de dicho quórum, el constituyente establece un requisito que tiende a la adecuada tipificación y penalidad de los delitos terroristas.

Sobre esa base, el inciso tercero del artículo $9^{0}$ de la Constitución dispone que "No procederá respecto de los delitos la amnistía ni el indulto, como tampoco la libertad provisional respecto de los procesados por ellos", añadiendo que tales delitos "serán considerados siempre comunes y no políticos para todos los efectos legales".

El proyecto que hoy debatimos propone tres enmiendas fundamentales a dicha normativa.

En primer término, se propicia hacer procedentes la amnistía y los indultos generales respecto de las personas condenadas por 
delitos terroristas, exigiéndose que las normas legales que confieren tales beneficios deban ser aprobadas por los dos tercios de los miembros en ejercicio de cada rama del Congreso Nacional.

En segundo lugar, se postula admitir la libertad provisional de los procesados por los referidos delitos, sujeta al requisito de que, elevada la resolución que la otorgue en consulta al tribunal de alzada, éste la apuebe por la unanimidad de sus miembros titulares.

Finalmente, respecto de los delitos terroristas, se sugiere mantenerlos excluidos de los indultos particulares que otorga el presidente de la República, contemplándose sólo la facultad de conmutar la pena de muerte por la de presidio perpetuo. Sin embargo, se incluye un artículo transitorio que permite al jefe del Estado indultar a quienes estén o sean condenados antes del 11 de marzo de 1990.

\section{Análisis juñdico}

Un análisis jurídico conceptual de los diversos aspectos expuestos, realizado con prescindencia de consideraciones de oportunidad y de efectos políticos, a los cuales aludiré más adelante, nos conducen a un juicio variado según las materias.

En efecto, resulta plausible considerar que siempre deba quedar abierta la amnistía para todo delito, ya que dicha institución suele ser la única vía para propender a la paz social luego de graves convulsiones políticas o sociales, sean de origen externo o interno. Así como la justicia individual representa una exigencia habitualmente esencial para el bicn común, acaecen coyunturas históricas de aguda anormalidad cívica, donde la integral administración de esa justicia debe ceder ante el imperativo prioritario de la paz social, en aras del mismo bien común de la sociedad.

Siguiendo tal criterio, parece lógico que si se opta porque siempre el legislador pueda amnistiar un delito, como mayor razón aquél debe encontrarse facultado para dictar leyes de indulto generales al mismo respecto, ya que éstas envuelven un perdón considerablemente más limitado que la amnistía.

Al formular estas consideraciones, no puedo dejar —eso sí- de representar la incongruencia que advierto entre este aspecto de la reforma constitucional que nos ocupa y una circunstancia que contradice manifiestamente la filosofia que la inspira. Me refiero a que Chile haya incorporado a su legislación instrumentos jurídicos internacionales que, 
según algunos, harían improcedente la amnistía respecto de determinados delitos. Más aún, el programa de la Concertación propone expresamente consagrar, a nivel constitucional, el predicamento de que no sean amnistiables los llamados "delitos contra la humanidad".

Si se estima que ciertos delitos, por su gravedad, deben quedar excluidos de la amnistía - como los crímenes de guerra o los denominados "delitos de lesa humanidad"-, considero que los cometidos por terroristas no debieran ser amnistiables, porque el ejercicio del terrorismo constituye hoy una de las más crueles y amenazantes expresiones de crimenes contemporáneos contra el hombre.

Por el contrario, si se asume el criterio de permitir la amnistía de los delitos terroristas, tal cual lo plantea el proyecto que hoy debatimos, éste debiera complementarse con las normas idóneas para evitar la contradicción e incongruencia a la que acabo de aludir.

Tocante a la admisibilidad de la libertad provisional para los delitos terroristas, debe tenerse presente que nuetra Constitución y la legislación que el Congreso Nacional acaba de aprobar para garantizar en mejor forma los derechos de los individuos, refuerzan considerablemente el derecho de toda persona a no verse privada de libertad mientras se la procesa, ya que la calidad del procesado no implica veredicto de culpabilidad.

Sin embargo, tanto la Carta Fundamental como la ley mencionada conservan ciertas excepciones tradicionales a ese derecho, por requerimiento perentorio de eficacia procesal o de prudencia en el resguardo del bien común. Entre esas excepciones se cuenta la potestad de los tribunales de justicia de denegar la libertad provisional, cuando ella entrañe un peligro para la seguridad de la sociedad.

Ahora bien, resulta casi axiomático que, si existen y subsisten presunciones fundadas de que una persona es responsable de un delito terrorista, su libertad provisional implica un peligro para la seguridad de la sociedad.

\section{Peligro para la sociedad}

Todo partícipe de un delito terrorista - por naturaleza misma de ésterepresenta un peligro para la seguridad de la sociedad. En efecto, la trágica eficacia del terrorismo depende y se nutre de una vasta red, en la cual los autores intelectuales, los ejecutores materiales y los que a 
sabiendas los ayudan o les facilitan sus acciones y coartadas, juegan un papel similarmente esencial y repudiable.

Obviamente, si en el transcurso del proceso desaparecen respecto de un procesado las presunciones fundadas sobre su responsabilidad en el delito, procederá dejar sin efecto su auto de procesamien to y decretar su absolución o el sobreseimiento temporal o definitivo, según corresponda.

Pero, si persisten las presunciones fundadas sobre la responsabilidad penal de una persona en un delito terrorista, se hace dificilmente imaginable que su libertad provisional no constituya un peligro para la seguridad de la sociedad.

Aun así, cabe reconocer que la realidad presenta siempre una variedad casuística que excede cualquier marco normativo abstracto. Así, por ejemplo, es posible que la presunta responsabilidad de un procesado esté llamada a derivar, en caso de sentencia condenatoria, en una pena a todo evento inferior al lapso de privación de libertad a que esa persona podría verse sometida por prisión preventiva, si el proceso se dilata mucho en el tiempo.

Hipótesis como esa hacen concebible la eventual conveniencia de no cerrar enteramente la libertad provisional respecto de una categoría determinada de delitos, aún tan graves como los de carácter terrorista, sobre la base de exigentes requisitos procesales para conceder dicha libertad en tales casos, como los que impone el proyecto de análisis.

No obstante, señor presidente, fluye de modo inequívoco que la médula de esta reforma constitucional radica en la facultad que se confiere al presidente de la República para conceder indultos particulares a quienes estén o sean condenados por delitos terroristas cometidos antes del 11 de marzo de 1990.

Por su impacto político y social, es aquí donde estriba lo esencial de este proyecto, más que en su preceptiva sobre la amnistía, los indultos generales o la libertad provisional. Así lo aprecia también la opinión pública.

Por tal razón, el convencido y resuelto rechazo de la Unión Demócrata Independiente a la norma que permite el indulto presidencial de terroristas, más allá de la conmutación de la pena de muerte por la de presidio perpetuo, nos lleva a anunciar nuestros votos contrarios al proyecto de reforma constitucional en debate. 
Permítanme una digresión, señor Presidente, para reafirmar mi punto de vista - otras veces expuesto en este Senado- en cuanto a que el otorgamiento de indultos particulares no debiera ser de resorte exclusivo del Presidente de la República, ya que ello, además de no ser propio de un régimen republicano, representa graves inconvenientes prácticos.

En efecto, tal realidad fomenta dos hipótesis igualmente inconvenientes. Por un lado, se presenta el riesgo de un ejercicio abusivo o políticamente discriminatorio de esa facultad, frente al cual no existe freno ni contrapeso jurídico alguno. Por el contrario, si el Presidente de la República desea hacer un uso prudente y moderado de tal atribución, el hecho de que ella sea de su exclusiva incumbencia lo expone a toda suerte de presiones inconvenientes, que resulta aconsejable evitar, $o$, al menos, atemperar.

Ninguna de las Constituciones que Chile turo desde la Independencia hasta 1925 radicó la facultad de conceder indultos particulares en el solo parecer del jefe del Estado.

\section{Error de 1925}

Sólo la Carta de 1925 incurrió en el error de concebir el indulto particular como una potestad omnímoda y exclusiva del Presidente de la República. La experiencia no fue afortunada. Desde muy diversas tendencias políticas surgieron iniciativas para corregir la norma constitucional pertinente $y^{\prime}$ restablecer el criterio que había prevalecido durante la mayor parte de nuestra vida republicana, en el sentido de exigir que, además de la voluntad presidencial, concurriese al efecto el acuerdo de otro órgano distinto del Ejecutivo.

Recogiendo esa experiencia, la Constitución de 1980 entrega al legislador un amplísimo margen para la regulación de los indultos particulares, al preceptuar que ellos serán otorgados por el jefe del Estado "en casos y formas que determine la ley".

Creo fundamental, señor Presidente, formar conciencia sobre el imperativo de establecer una normativa jurídica en virtud de la cual la concesión de indultos particulares por el Presidente de la República deba, en general, requerir el acuerdo previo de un órgano independiente del gobierno.

Superadas las pasiones políticas que este tema suscita en nuestra actual coyuntura histórica, presentaré un proyecto de ley en tal sentido. Entretanto, reitero mi exhortación a que se reflexione sobre esta 
materia, a fin de que oportunamente podamos abordarla en nuestro trabajo legislativo, aprovechando el acierto de la Carta Fundamental vigente que ha situado el tema en la órbita de la legislación común.

Ahora bien, los delitos terroristas representan la única excepción a tal potestad legislativa, por cuanto el constituyente los excluyó expresamente de los indultos particulares, conforme al texto vigente del artículo $9^{\circ}$ de la Constitución.

Resulta sintomático y sugerente que los autores del proyecto que hoy debatimos, mantengan en la preceptiva constitucional permanente la prohibición de que el jefe de Estado conceda indultos particulares a personas condenadas por delitos terroristas, admitiendo sólo a conmutar la pena capítal por la de presidio perpetuo, lo que estimo adecuado y razonable.

Ello revela que los propios impulsores de la iniciativa en análisis reconocen que la gravedad del terrorismo reclama excluir tales delitos del indulto presidencial, reservando para ellos sólo la amnistía o los indultos generales, que competen al legislador y no a la persona del jefe del Estado. Más aún, el quórum de dos tercios de los miembros en ejercicio de cada Cámara que se propone para aprobar dichas leyes de amnistía o de indultos generales, refuerza la evidencia señalada.

Pero he aquí que el proyecto contempla una excepción. Quienes estén o sean condenados por delitos terroristas cometidos antes del 11 de marzo de 1990, podrán ser indultados por el primer mandatario.

Señor Presidente, nadie ignora que esta iniciativa apunta a beneficiar a ciertos procesados o condenados por leyes especiales que suelen denominarse equivocadamente "presos políticos".

Lo esencial es que la ciudadanía tenga perfectamente claro cuál es el alcance preciso del proyecto sobre el que hoy se pronunciará el Senado.

En los próximos días se promulgarán diversas normas legales tendientes a agilizar los procesos de esas personas. Para tal propósito, se contemplan incluso cambios de competencia. Dichas modificaciones legales contaron con la aprobación unánime del Senado.

\section{Juzgamiento adecuado}

En lo que concieme a nuestro partido concurrimos a aprobar en ambas Cámaras los referidos textos, que pronto serán preceptos legales, porque, 
aunque consideramos que los mal llamados "presos políticos" están inculpados de actos que en cualquier época o latitud importan graves delitos contra la sociedad y contra los derechos humanos, creemos que - como toda persona- ellos merecen un juzgamiento adecuado y justo.

En consecuencia, de acuerdo a esas normas, el Presidente de la República - sin necesidad de una reforma- podría indultar dentro de poco tiempo, una vez dictadas las sentencias respectivas, a todos los denominados "presos políticos", salvo los condenados por delitos terroristas.

La ciudadanía debe saber asî que esta iniciativa tiene por objeto preciso que el jefe del Estado también pueda indultar terroristas. Eso es lo que juzgamos grave y profundamente peligroso para el país. Y ahí estriba el motivo principal que nos lleva -por un imperativo de conciencia- a rechazarla.

Para auspiciar el proyecto en debate, se han esgrimido cinco argumentaciones principales de las cuales estimo necesario hacerme cargo en esta oportunidad.

En primer término, se invoca que el programa de gobierno de la Concertación contempla el indulto de los que denomina "presos políticos", salvo respecto de quienes resulten responsables de homicidios, de lesiones gravísimas y de secuestro o sustracción de menores.

Tal antecedente hace explicable que el actual gobierno busque los caminos jurídicos para cumplir con ese compromiso programático. Pero nuestro partido considera que quienes durante la última campaña presidencial y parlamentaria impugnamos enérgica y fundamentalmente ese acápite del programa de la Concertación, debemos ser consecuentes ante el país y ante nuestro electorado, no sumándonos a un objetivo que no compartimos ni ayer ni ahora. En segundo lugar, se esgrime que la facultad de indulto en cuestión se estaría confiriendo nominativamente a don Patricio Aylwin Azócar, como un acto de confianza en la sabiduría y prudencia con que la ejercerá. Tal vez ese Fredicamento explique que el proyecto ni siquiera restrinja de modo a.guno la atribución de indulto presidencial que se propicia, haciéndola así potencialmente extensiva incluso a los condenados por delitos que el propio programa de la Concertación plantea excluir el beneficio.

Semejante enfoque no puede ser más equivocado e impropio de un estado de derecho. Desde luego, no es efectivo que la norma transitoria de la Constitución que el proyecto sugiere, esté destinada a ser aplicada sólo por don Patricio Aylwin. Aún prescindiendo de la 
eventualidad - siempre posible - de alguna desgracia personal que impidiese al actual jefe del Estado ejercer su cargo hasta el fin de su período, la facultad de indultar terroristas que propone el proyecto seguirá vigente indefinidamente respecto de los condenados por delitos de ese carácter, cometidos antes del 11 de marzo de 1990.

\section{Interrogante a futuro}

De consiguiente, quienes no merezcan el indulto a juicio del actual jefe del Estado podrian ser indultados -dentro de tres años- por quien le suceda constitucionalmente en su cargo, cuyo nombre y calidades personales obviamente desconocemos.

Ello acentúa lo impropio de aprobar normas jurídicas basadas en juicios personales y subjetivos acerca de quien desempeña una función pública en un instante determinado. El régimen democrático supone la impersonalidad de la ley. Discurrir en una línea distinta conlleva un delicado precedente, el cual pronto podría incluso volverse contra quienes lo generen.

Por otra parte, remitiéndonos aún al ejercicio de la facultad en cuestión por quien hoy desempeña la primera magistratura, el argumento en referencia me suena incomprensible en labios de los que han manifestado su pública discrepancia con el programa de la Concertación en materia de indultos a los denominados "presos políti$\cos { }^{n}$.

No se trata de que hagamos una mayor o menor valoración de las condiciones éticas y prudenciales del actual Presidente de la República. No reside ahí el problema. La cuestión estriba en que don Patricio Aylwin comparte el programa de la Concertación y, obviamente, procederá conforme a él. ¿Podemos, entonces, quienes hemos disentido ante la ciudadanía del contenido de ese programa en esta materia, concurrir a ampliarle al Presidente de la República su facultad de indulto para que él la pueda ejercer también respecto de terroristas?

Nadie que vote aquí por la aprobación del proyecto que debatimos podrá eximirse de su propia responsabilidad en el futuro otorgamiento de un indulto a cualquier terrorista que el programa de la Concertación incluya entre quienes, a su juicio, lo merecen, ya que ello será el fruto enteramente previsible de la aprobación del proyecto en debate. En tercer término, se sostiene que los denominados "presos políti- 
$\cos ^{”}$ delinquieron básicamente porque en nuestro país imperaba un gobierno militar. Se presume así, que restablecido el régimen democrático, dichas personas abandonarán la subversión y la violencia.

Ese supuesto, que podría ser válido en ciertos casos muy determinados, no resulta generalizable.

No tenemos derecho a olvidar que el presidente Allende invocó similar raciocinio para indultar a quienes apodó él "jóvenes idealistas". Auguró que, bajo un gobierno como el suyo, ellos no reincidirían en la violencia delictual. A los pocos meses, el ex ministro del Interior don Edmundo Pérez Zujovic moría acribillado por las balas asesinas de un comando terrorista que integraban los hermanos Rivera Calderón, quienes habían recobrado su plena libertad merced del indulto presidencial, en calidad de "jóvenes idealistas".

Al votar este proyecto, confio en que todos tengamos muy presentes aquella trágica experiencia.

En cuarto lugar, para favorecer esta reforma constitucional, se afirma que entre los terroristas a quienes ella podría beneficiar hay quienes han sufrido injusticias procesales o apremios ilegítimos. Me parece muy malo el argumento.

Para superar o rectificar eventuales irregularidades de carácter procesal, el camino idóneo es introducir los correctivos apropiados en ese mismo ámbito. Así lo entendió el Senado cuando aprobó normas legales permanentes y transitorias para garantizar en mejor forma los derechos de las personas, con muy significativas modificaciones al proyecto patrocinado por el gobierno y aprobado inicialmente por la Cámara de Diputados.

A quienes preguntan a cuántos días, meses o años de presidio equivale el sufrimiento de una tortura, les respondo que a ninguna cifra. Por eso mismo, las penas no incluyen como aceptable ningún trato cruel, inhumano o degradante. No son realidades intercambiables. Colocar en igual órbita la duración de una condena y los apremios ilegítimos que el condenado haya sufrido, para sumarlos o restarlos en búsqueda de una supuesta compensación, aparece así como un despropósito jurídico aberrante.

En la otra punta del arco, el mismo raciocinio sobresale también en su falacia.

¿Puede alguien sostener seriamente que una persona que ha cometido un grave delito y que representa una amenaza potencial para sus semejantes debe ser liberada porque ha sido objeto de apremios ilegítimos? ¿O que, por igual motivo, los tribunales de justicia debieran 
conceder la libertad provisional a una persona cuya prisión preventiva sea necesaria para la seguridad de la sociedad? ¿Quién se responsabilizaría de ello ante la comunidad nacional y ante las futuras víctimas del delincuente o reo así liberado?

\section{Responsabilidad del Estado}

Al Estado compete extremar sus esfuerzos para identificar y castigar al que tortura. También resulta válido que se repare o indemnice a quienes se compruebe que han sufrido tales maltratos. Pero ello no puede vincularse a lo que deba determinar la sentencia judicial respectiva, ni tampoco a los elementos de juicio para decicir si procede o no el otorgamiento de un indulto. Una cosa es que el torturador deba ser sancionado, y otra muy distinta que el torturado deba ser liberado.

Subrayo con especial énfasis los alcances de la perturbación de criterios que estoy refutando, porque, si ella se acepta, la actual autoridad gubernativa se verá encajonada frente a una realidad inmanejable. El propio enunciado programático de la Concertación de excluir del indulto a los culpables de algunos delitos gravísimos, sería cuestionado por quienes - con fundamento de hecho o sin él- aleguen haber sufrido maltratos y ser acreedores a que ello les sea compensado a través del indulto.

Ignoro si ya no será demasiado tarde para contrarrestar ese peligro. Pero formulo la prevención expuesta, al menos porque estoy cierto de que la aprobación de esta reforma transformará ese riesgo en un fenómeno virtualmente incontenible.

Finalmente, una quinta línea de argumentaciones en favor del proyecto en debate lo sitúa en la perspectiva de la reconciliación nacional. A mi juicio, ella apunta, sin duda, a la más importante de las ópticas con que cabe aproximarse al tema.

Chile vivió durante los últimos veinticinco años un cuadro traumático de polarización política y de proyectos excluyentes, donde el odio entre compatriotas se atizó y se acentuó hasta culminar en un cuadro de guerra interna, con las dolorosas secuelas que todos hemos vivido.

Superar tal realidad supondrá dar vuelta ciertas hojas del pasado, aunque extrayendo de él las lecciones que nos demandan el presente y el futuro. Ello reclamará asumir peligros y superar desconfianzas, con recíproca generosidad y madurez de todos los sectores nacionales. 
Aun así, es menester observar sumo esmero para fijar las bases de la reconciliación nacional en forma cuidadosa y realista. Equivocarse en las fórmulas que se adopten puede frustrar una oportunidad que dificilmente se reedite con iguales auspicios para lograr el objetivo descrito.

En esa inspiración nuestro partido apoyó el denominado "acuerdo marco" que al respecto se alcanzó en la Comisión de Constitución, Legislación, Justicia y Reglamento de la Cámara de Diputados. Saltan a la vista sus notorias ventajas y sus radicales diferencias, comparado con el proyecto que nos ocupa.

Mientras aquel "acuerdo marco" implicaba una precisa rebaja de penas que excluía los delitos más graves, este proyecto abre un indiscriminado indulto presidencial para cualquier delito. Mientras el "acuerdo marco" abarcaba equilibradamente los diferentes delitos cometidos durante el gobierno anterior, sin distinciones de bandos, este proyecto sólo beneficia a los responsables de delitos terroristas, sesgando así su alcance a uno solo de los bandos en que se dividió nuestra patria.

En fin, mientras en el "acuerdo marco" el Congreso Nacional y todos los partidos en él representados asumíamos directa y plenamente nuestra responsabilidad plasmando una fórmula legislativa, este proyecto delega sustantivamente esa responsabilidad nuestra en el criterio casuístico del Presidente de la República.

\section{Conducias políticas}

Es posible que cuando ese "acuerdo marco" fue suscrito aún no estuviesen dadas en el país las condiciones para asumirlo, o que sus términos no fuesen plenamente satisfactorios para todos. Respetamos, aunque no compartimos, la conducta de quienes inicialmente lo suscribieron y luego lo desestimaron.

En todo caso, intuyo que, más pronto que distante en el tiempo, habremos de abordar el desafio de superar — de modo global y definitivo- los hondos quiebres que el último cuarto de siglo provocó en nuestra convivencia, con soluciones acaso aún más amplias que las de aquel "acuerdo marco" respecto de todos los bandos en que Chile fue trágica y fratricidamente dividido.

Así como nuestro partido respaldó el referido "acuerdo marco", contribuiremos a cualquier esfuerzo que se inscriba en una inspi- 
ración semejante. Pero las mismas razones que nos impulsarán a ello nos obligan, en cambio, a rechazar un proyecto como el que hoy debatimos, que se aparta de los requisitos más elementales para ser considerado como instrumento eficaz, equitativo y prudente hacia una auténtica reconciliación nacional.

Señor Presidente:

No quisiera finalizar esta intervención sin advertir las implicancias de este proyecto en relación con sus efectos políticos más amplios.

\section{Las 54 reformas}

Hace apenas un año y medio la ciudadanía ratificó plebiscitariamente, por abrumadora mayoría, un conjunto de 54 reformas a la Constitución de 1980, como fruto de un acuerdo político entre el gobiemo militar y la totalidad de los partidos democráticos.

Al participar de esa reforma constitucional de consenso, la Unión Demócrata Independiente destacó que su aprobación exigía un lapso razonable de plena vigencia de la institucionalidad así modificada, sin que se impulsaran nuevas reformas a la Carta Fundamental, a fin de poder evaluarla en su in tegral aplicación práctica, hasta formarse un juicio decantado al respecto.

Seguimos manteniendo ese criterio. Creemos que se debería diferir el estudio y aprobación de cualquier reforma constitucional, al menos hasta 1993, con la única excepción de aquellas enmiendas muy precisas que fueren adecuadas, indispensables y urgentes para una conveniente concordancia constitucional con los tratados internacionales ratificados por Chile y que se encuentren vigentes.

Las ventajas de la estabilidad institucional para afianzar la consolidación democrática en las circunstancias que vivimos, como asimismo para fortalecer la confianza de los agentes económicos internos y externos en nuestro esquema de desarrollo, resaltan en forma demasiado nítida para extenderse al respecto.

Sin embargo, en amplios sectores de la dirigencia pública chilena, pareciera no registrarse suficiente conciencia acerca de los riesgos o perjuicios a que podria exponernos un ambiente de inestabilidad institucional.

En política, en economía o en cualquier esfera de la vida social, el mérito de una alteración determinada a la normativa existente 
no puede ponderarse sin medir los negativos efectos de incertidumbre que pueden arrojar los cambios en las reglas del juego. A veces ello hace preferible incluso no introducir una modificación que en sí misma fuere atinada, por el valor prioritario que encierre la estabilidad institucional.

Lo anterior vale especialísimamente para la Constitución Política de la República, que es la ley de las leyes. O la Carta Fundamental de un país es razonablemente estable, o ella no cumplirá su función de encauzar en forma adecuada la convivencia ciudadana.

No es una simple coincidencia, señor Presidente, que la época de mayor estabilidad política y progreso social de Chile se diera bajo la Constitución de 1833 , cuya primera reforma se aprobó más de cuarenta años después de su entrada en vigencia.

No resulta tampoco ajeno o casual que en un solo lapso de los diez años precedentes al colapso de nuestra democracia que culminó en 1973, se aprobara la friolera de seis reformas constitucionales sucesivas, la última de las cuales ni siquiera alcanzó a regir.

Aprobar esta reforma constitucional que ahora se nos propone, resulta particularmente inoportuno si se considera que amplios sectores de la Concertación gobernante proclaman a los cuatro vientos su propósito de impulsar un cúmulo de otras enmiendas constitucionales medulares, cuyo contenido delata que subsiste dentro de ese conglomerado la voluntad de desmantelar la institucionalidad vigente.

Sólo el tiempo permitirá dimensionar la magnitud del error político de quienes, no compartiendo ese propósito destructor de la institucionalidad que nos rige, se sumen hoy a posibilitar la aprobación de este proyecto de reforma constitucional.

\section{Estabilidad institucional}

Trizada de hecho la confluencia en la defensa de la estabilidad institucional de quienes naturalmente estamos llamados a asumirla, resultará muy dificil evitar el efecto de "cascada" frente a las próximas reformas constitucionales que nos serán presentadas. Que nadie se mueva a engaño al respecto. Si se aprueba este proyecto, entraremos a un nuevo escenario -que inevitablemente acarreará nuevas actitudes- frente al tema de las reformas constitucionales, con notorio detrimento para la estabilidad institucional.

Particular desconcierto público produciría que nos aventurásemos en esa dinámica de cambios constitucionales, empezando por 
uno como éste. Más allá de la validez o plausibilidad conceptual de algunos aspectos de este proyecto, a los que me referi en la primera parte de esta intervención, nunca cabe olvidar que las normas jurídicas deben resolverse considerando su oportunidad y los efectos con que ellas repercutirán sobre el cuerpo social.

¿Cómo entenderá la opinipón pública que la primera reforma constitucional que este Senado aprobare se dirija a atenuar la drasticidad de la normativa contra el terrorismo, alterando para ello un precepto que conforma las bases de la institucionalidad chilena? ¿Es éste el momento oportuno para hacerlo, aún en aquellos tópicos que todos pudiésemos -en abstracto- estimar plausibles? La creciente vinculación entre el terrorismo y el incremento de la brutalidad que se observa en la delincuencia común, ¿no es acaso una campanada adicional de alerta, suficiente para remecer la sensibilidad de toda persona con mediano sentido de la realidad?

Señor Presidente:

No podemos sumarnos a un proyecto cuya aprobación dañaría la defensa de la estabilidad institucional hacia el futuro.

No podemos plegarnos a una iniciativa que lanza una señal pública equivoca de debilitamiento jurídico frente al terrorismo.

No podemos, en fin, apoyar una reforma constitucional cuyo principal alcance político consiste en permitir el indulto presidencial de terroristas, porque al entregar esa llave juridica al actual o a cualquier otro jefe de Estado, sentiriamos cargar sobre nuestras conciencias con la responsabilidad moral de las consecuencias que se deriven de su ejercicio, que todo permite avizorar que serán luctuosas.

JAIME GUZMÁN ERRÁZURIZ 